Proceedings of XIX International Scientific Conference "New Technologies and Achievements in Metallurgy, Material Engineering, Production Engineering and Physics", Częstochowa, Poland, June 7-8, 2018

\title{
The Research of Selected Properties and Structure of Polymeric Material Modified with Hard Coal Ash
}

\author{
A. Gnatowski* And E. KaziK \\ Częstochowa University of Technology, J.H. Dąbrowskiego 69, 42-201 Częstochowa, Poland
}

\begin{abstract}
The aim of the study was to investigate selected properties and structure of polymeric material modified with hard coal ash. The investigation provides information on the types of modifications due to physical and chemical changes and analysis of selected research methods. The study included polymer structure testing, ball hardness determination, Shore's hardness determination, tensile strength determination, crystallinity and phase transition temperature by differential scanning calorimetry, thermal analysis of polymeric materials by dynamic mechanical thermal analysis and colorimetric method. From the presented research it can be stated that the higher the content of hard ash in polyethylene, the harder it becomes, although less resistant to stretching. The addition of ash lightly affected the degree of crystallinity. The last stage of the study was to analyze the surface resistance depending on the difference in the amount of filler. The important effect of the increase in ash content of hard coal was a significant change in properties of composites. In summary, the intended goals were presented in the paper.
\end{abstract}

DOI: 10.12693/APhysPolA.135.119

PACS/topics: polymer composites, coal ash, thermomechanical properties

\section{Introduction}

The properties of polymeric materials can be modified by adding various types of fillers. The type and properties of the filler and polymer matrix determine the properties of the composite. Research carried out so far has allowed the development and introduction to the production of composites with very good strength, thermal and electromagnetic properties [1-6]. The paper presents the results of research on high-density polyethylene modified with fly ash. Polyethylene is a thermoplastic, partly crystalline material, applicable in many industries $[1,5,7]$. The main purpose of polyethylene modification was to improve the ability to suppress mechanical vibrations, stiffness and change many other functional properties allowing for wider use of the produced material. Prediction of properties and conditions of use has a large role in the planning of the composition as well as in the preparation of polymer products $[2,3,8,9]$. The paper presents the results of research on the effect of added fly ash from hard coal combustion in pulverized coal boilers, on the properties of polyethylene. The research included differential scanning calorimetry (DSC) analysis, dynamic properties by dynamic mechanical thermal analysis (DMTA), supermolecular microstructure.

\section{Material and methods}

High-density polyethylene (PE-HD) under the trade name of Hostalen GC 7260, made by Lyondell Basell Industries Holdings, was used for making the samples. Fly ash from the Połaniec Power Plant ENGIE Energia Polska S.A. was used as a filler. The composites

\footnotetext{
* corresponding author
}

were made by extrusion. Samples for testing were injected using the KRAUSS MAFFEI KM65 - 160C1 injection molding machine with a screw with a diameter of $30 \mathrm{~mm}$, ratio of an $L / D=23$ and a mold closing force of $650 \mathrm{kN}$. Optimal properties of the tested samples were obtained with the following injection parameters: injection pressure $60 \mathrm{MPa}$, hold pressure $30 \mathrm{MPa}$, hold time $28 \mathrm{~s}$, cooling time $15 \mathrm{~s}$, mold temperature $40^{\circ} \mathrm{C}$, nozzle temperature $205^{\circ} \mathrm{C}$.

In the DSC thermal properties tests, the degree of crystallinity of the polymeric material and the temperature range of the crystalline phase were determined. The tests were carried out using a Netzsch DSC 200 PC calorimeter. In order to minimize the effect of the epidermis the core, DSC samples were cut perpendicularly to the direction of flow from samples of composites obtained by injection molding. PC 200 NETZSCH software was used to determine the degree of crystallinity. DSC curves were recorded when heating samples at a rate of $10^{\circ} \mathrm{C} / \mathrm{min}$ in the temperature range from 25 to $250^{\circ} \mathrm{C}$. Tests of dynamic mechanical properties were made using the DMA 242 device from NETZSCH with a handle for three-point bending of sample in the form of a beam with dimensions of $50 \times 10 \times 4 \mathrm{~mm}$. The prepared sample was placed in a holder and then subjected to variable sinusoidal force with different frequency $(1,10,50 \mathrm{~Hz})$. On the basis of deformation and force (taking into account the dimensions of the sample), the value of the conservation modulus $E^{\prime}$, loss modulus $E^{\prime \prime}$ and $\tan \delta$ in the function of temperature was calculated $[7,10,11]$. The supermolecular structure was investigated using a polarization-interference microscope Nikon Eclipse E200 microscope at $400 \times$ magnification. The research samples were made using the Thermo Scientific ME Microtome. 


\section{Measurements}

Figure 1 shows DSC thermograms of polyethylene and composites with fly ash.

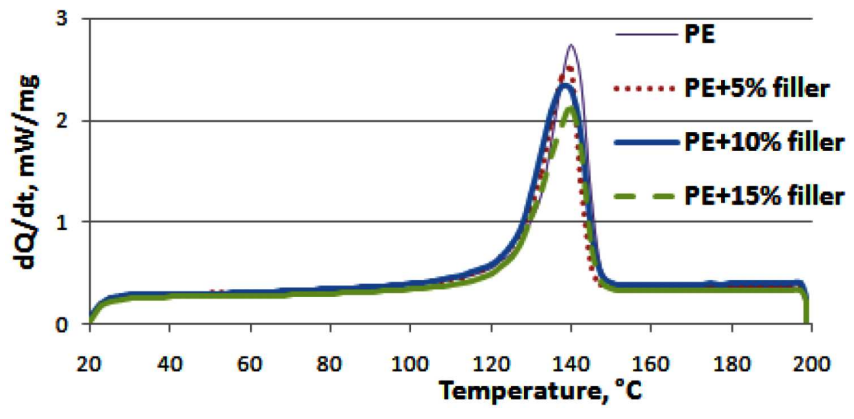

Fig. 1. DSC thermograms of polyethylene and composites.

TABLE I

The results of DSC investigations obtained from calculations of the Netzsch Proteus programme.

\begin{tabular}{l|c|c|c}
\hline \hline Polymer & $\begin{array}{c}\text { Max. melt } \\
\text { temp. }\left[{ }^{\circ} \mathrm{C}\right]\end{array}$ & $\begin{array}{c}\text { Melting } \\
\text { range }\left[{ }^{\circ} \mathrm{C}\right]\end{array}$ & $\begin{array}{c}\text { Crystallinity } \\
\text { degree [\%] }\end{array}$ \\
\hline $\mathrm{PE}$ & 140.2 & $129.4-146.5$ & 64.37 \\
$\mathrm{PE}+5 \%$ filler & 138.5 & $125.1-145.9$ & 61.16 \\
$\mathrm{PE}+10 \%$ filler & 139 & $126.7-144.1$ & 57.65 \\
$\mathrm{PE}+15 \%$ filler & 139.8 & $126.9-144.3$ & 52.90
\end{tabular}
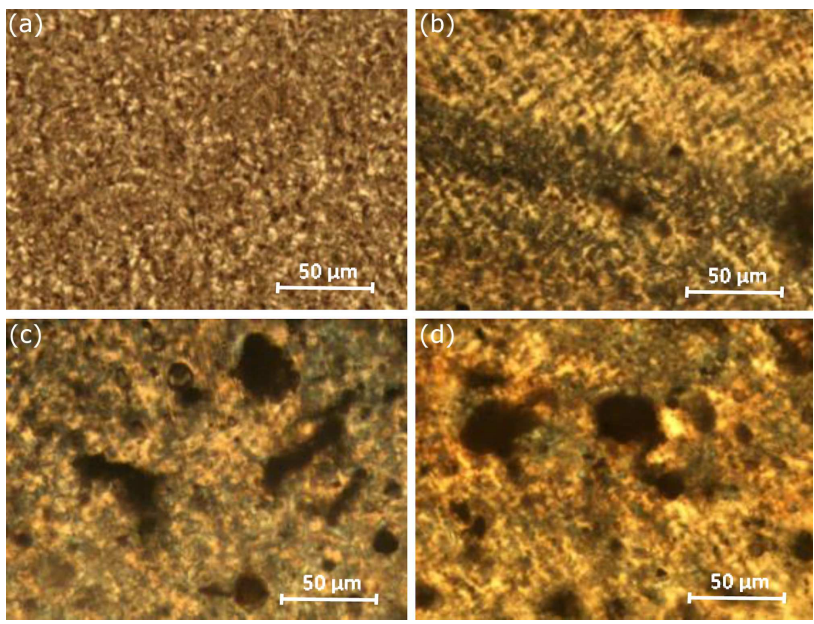

Fig. 2. Microstructure observed under optical microscope at $400 \times$ magnification: (a) PE-HD, (b) PE-HD $+5 \%$ ashes from hard coal, (c) PE-HD $+10 \%$ ashes from hard coal, (d) PE-HD $+15 \%$ ashes from hard coal.

The value of the degree of crystallization was calculated according to (1) considering the measured melting enthalpy. The result is referred to the percent filler content

$$
S_{K}=\frac{\Delta H_{m}}{w_{c} \Delta H_{k}} 100 \%,
$$

where: $\Delta H_{m}$ - melting enthalpy of the tested material, $\Delta \mathrm{H}_{k}$ - melting enthalpy of a completely crystalline material, $w_{c}$ - mass fraction of homopolymer being part of the tested material $[9,10]$.

The highest value of the degree of crystallinity was obtained for composite samples with $5 \%$ content of fly ash. Due to the increase in the content of the filler, the crystallinity degree value decreased, while the crystalline melting temperature range was narrowed. The maximum melting temperature has changed slightly (Table I). These changes confirm the strengthening role of the filler particles dispersed in polyethylene. The results indicate that composites with a lower filler content have an increased crystallization ability.

Figure 2 shows the supermolecular microstructure of polyethylene with different content of hard coal ash.

In the case of polyethylene, the structure is regular and orderly. Studies on the structure of polyethylene composites by optical microscopy have shown the fragmentation of the crystal structure (Fig. 2b-d). As a result of the addition of the filler, the structure of polyethylene has changed, it has been noted that the structural elements are reduced, especially in the case of higher filler contents.

Figure 3 shows the changes of the conserving module $E^{\prime}$ and the mechanical loss factor of composites produced with different filler contents as a function of temperature and frequency. The relaxation process is responsible for the first reduction in $E^{\prime}$ in all cases. As the temperature rises, there is a second reduction in the conservative module corresponding to the relaxation process of the $\mathrm{PE}$ amorphous regions. The system is in a state of thermodynamic imbalance. In the tested temperature range $\left(20^{\circ} \mathrm{C}\right.$ to $\left.120^{\circ} \mathrm{C}\right)$, in the set frequency of deformations of 1,10 , and $50 \mathrm{~Hz}, E^{\prime}$ values of composites containing hard coal ash are significantly higher than $E^{\prime}$ of unfilled PE. The conservative module of the sample containing $5 \%$ by weight of the filler at $25^{\circ} \mathrm{C}$ is $2123 \mathrm{MPa}$. The polymer matrix of the composite containing $15 \%$ by weight of the filler is most strongly strengthened with ash particles which indicates a high degree of dispersion of the

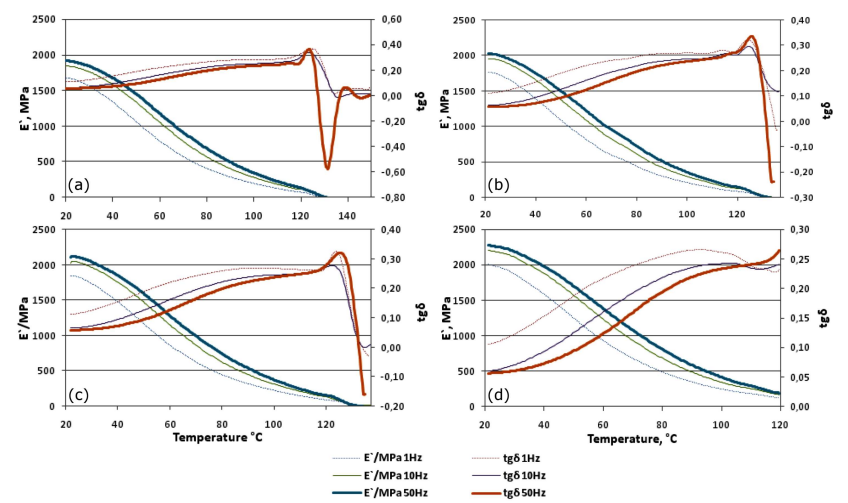

Fig. 3. The values of the conservative modulus $E^{\prime}$ and $\tan \delta$ as a function of temperature at different frequencies for: (a) PE, (b) PE $+5 \%$ fly ash, (c) PE $+10 \%$ fly ash, (d) PE $+15 \%$ fly ash. 
filler in the sample. It is worth noting that composites containing $10 \%$ and $15 \%$ filler have a similar and higher $E^{\prime}$ value over the entire temperature range, compared to an unfilled polymer. The filler particles therefore exert a strong strengthening effect on the material in all tested compositions. From the DMTA tests it is possible to determine changes in the stiffness of the tested material. It is possible by analyzing the change in the value of the maximum of the mechanical loss angle. The addition of ashes causes the maximum of the mechanical loss angle to be shifted towards the higher temperature and decreases with the shift towards the lower temperature with the increase of ash content. The shifting of the reflections may be the result of the increasing stabilization of the composites resulting from the immobilization of PE crystallite fragments by the filler particles.

\section{Conclusions}

The addition of fly ash from the combustion of hard coal to polyethylene advantageously changes the dynamic mechanical and thermal properties of the tested material. On the basis of the DSC tests, a slight decrease in the crystalline phase of the polymer matrix was found for the composite samples. The only exception is the material with a lower filler content, but the melting temperature range has not changed significantly. DSC analysis indicates that the addition of fly ash to PE has little effect on changes in melting point. The addition of ashes significantly changes the value of the degree of crystallinity and stiffness of the polymer composites. In the tested filler content range, the influence of this parameter on the temperature value of phase transitions of polymeric-fly ash composites is slight. This can be explained by the crystalline structure constrained by the filler particles during cooling of the composites. The influence of a larger amount of filler is smaller, which results in a smaller reinforcing effect of the filler. The tested composites have better thermomechanical properties than unfilled PE, whereas composites with a filler content of $10 \%$ and $15 \%$ are characterized by a larger conserving module in the temperature range 20 to $120^{\circ} \mathrm{C}$. In the case of composites, the mechanical loss factor as a function of temperature and frequency has changed significantly. A significant influence of the filler on the microstructure of the tested materials was also found, with the largest changes recorded at the highest $15 \%$ filler content.

\section{References}

[1] D.V. Rosato, M.G. Rosato, N.R. Schott, Plastics Technology Handbook, Momentum Press, New York 2011.

[2] S.B. Singh, S. Ray, J. Mater. Process. Technol. 143144, 623 (2003).

[3] A. Gnatowski, A. Ziewiec, R. Gnatowska, AIP Conf. Proc. 1648 (2015).

[4] A. Jakubas, P. Jabłoński, Measurement 108, 34 (2017).

[5] G.W. Ehrenstein, Polymeric Materials, Hanser Publishers, Munich 2001.

[6] A. Jakubas, P. Gębara, S. Seme, A. Gnatowski, K. Chwastek, Acta Phys. Pol. A 131, 1289 (2017).

[7] J. Koszkul, Polymer Materials, Częstochowa University of Technology, Częstochowa 1999.

[8] K.P. Matabola, A.R. de Vries, A.S. Luyt, R. Kumar, Express Polym. Lett. 7, 635 (2011).

[9] M. Alonso, J.I. Velasco, J.S. de Saja, Eur. Polym. J. 33, 255 (1997).

[10] R.E. Wetton, R. De Blok, P.J. Corish, Int. Polym. Sci. Technol. 18, 163 (1991).

[11] K.P. Pramoda, T. Liu, J. Polym. Sci. Part B Polym. Phys. 42, 1823 (2004). 